\title{
POSSIBILITIES OF APPLYING BIOSORPTION SYSTEMS FOR BALLAST WATER TREATMENT
}

\author{
Viktoras Racys \\ Irmantas Valunas \\ Inga Urniezaite \\ Kaunas University of Technology, Lithuania
}

\begin{abstract}
This article represents applying of biosorption process for the treatment of wastewater, contaminated with light oil products. SC "Klaipedos nafta", which works in the field of transshipment of oil and its products in Lithuania, has installed biosorbers for the treatment of ballast and bilge water from the vessels. Biosorption process is sustained by integrated running of the Granulated Activated Carbon (GAC) and the active branches of particular microorganisms. This wastewater treatment method is preeminent for treatment of this kind of wastewater, comparing with the treatment efficiency of other methods. Wastewater is pumped into biosorbers after flotation and remaining concentration of Total Petroleum Hydrocarbons (TPH) varies about $2 \mathrm{mg} / \mathrm{l}$. At the very beginning of the biosorbers operation wastewater treatment efficiency of $0.2 \mathrm{mg} / \mathrm{l}$ was reached. For the process control main parameters are being analyzed: sorption capacity of the activated carbon, biomass amount and enzymatic activity of the microorganisms. Interdependence of the values of these parameters and treatment efficiency according to TPH is being established. Obtained results support the theory of biosorption process and the process workability for the treatment of wastewater, polluted with light oil products. In this article there are given principle technological solutions and parameters of the biosorbers in SC "Klaipedos nafta".
\end{abstract}

\section{KEYWORDS}

Biosorption application; Petroleum hydrocarbons treatment; Ballast and bilge waste water treatment; Wastewater treatment efficiency

\section{INTRODUCTION}

During oil extraction, transportation and use, natural waters are often polluted with oil hydrocarbons. When these compounds get into environment, ecosystems are destabilized, part of flora and fauna is lost. In the human's organism, oil hydrocarbons can cause different diseases, including cancer [1]. Because of its environmental risk, these compounds must be eliminated from the wastewater. In the laws of national environmental protection organization permissible norms of oil hydrocarbons in the water are stated. In Lithuania their concentrations in water should not exceed $1 \mathrm{mg} / \mathrm{l}$. 
For wastewater, contaminated with oil products, treatment stationery equipment is used. For the pretreatment gravitational separation, coalescence and flotation are usually used. The experience of companies, working with oils products shows, that if oil products are strongly emulgated or wastewater is contaminated with light oil products - petroleum, aviation fuel or diesel, then it is not enough to use mechanical treatment, if we want to clean water to the right norms - wastewater has to be treated additionally. In such a case, technological scheme often is supplemented by biological, chemical or biochemical treatment methods.

Currently, for wastewater, contaminated with oil products, treatment, biochemical treatment is often used. This kind of treatment is based on microorganism ability to biodegrade oil hydrocarbons. Self-contained water treatment would take a long time, so active branches of particular microorganisms, able to biodegrade hydrocarbon substrates, are used to accelerate this process. Research projects prove that the best microorganism's genus for oil contaminants treatment is Arthrobacter bacterium [1]. Mixed cultures of microorganisms, together with actinomycetes, protozoa, fungus, algae, etc, form biomass, which is able to biodegrade different oil hydrocarbons and to form stable ecosystems, more resistant to environmental changes $[2,3]$.

Mixed systems of biochemical treatment can be combined with sorption processes. For this purpose, instead of usual medium load, medium with sorption characteristics for particular substances can be used. This type of modified mixed biochemical treatment systems, also named biosorption systems are more and more often used for stable organic compounds removal $[3,5]$. This method's usage mechanism and factors, influencing treatment process are still under research, but obtainable treatment efficiency and process stability shows preeminence, comparing with other treatment ways. Analysis of literature sources [1-7] shows practical use tendency of mixed and modified systems for stable and toxic compounds removal.

This article presents biosorption system, created by KUT Assoc. Prof. V. Racys and installed in SC "Klaipedos nafta". The main parameters of its efficiency and control are given. The main objective of this article is to value industrial biosorbers suitability for deep treatment of wastewater, contaminated with oil products.

\section{RESEARCH METHODOLOGY}

Research was made in biosorbers, which were installed and started to operate in July 2005, in $\mathrm{SC}$ "Klaipedos nafta". The principle scheme of the process is given in Figure 1.

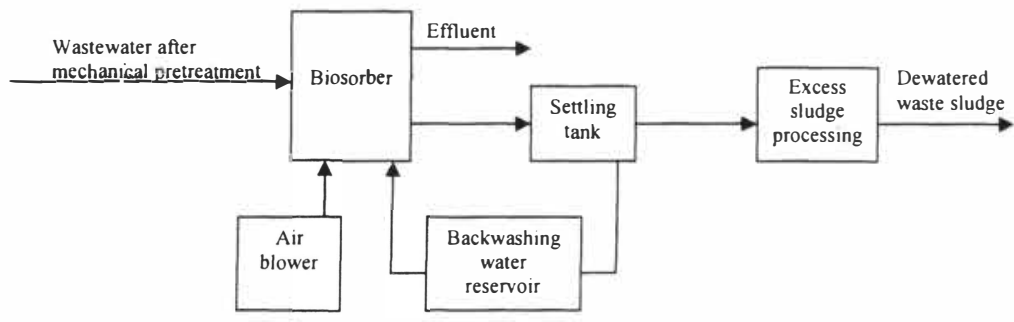

Figure 1. Principle scheme of biosorption process. 
Biosorbers in SC "Klaipedos nafta" works in SBR mode, they are filled, aerated and emptied in turns. Principle scheme (see Figure 1) shows, that untreated wastewater with average concentration of oil products $3 \mathrm{mg} / \mathrm{l}$ goes to the flotator, where it is pretreated mechanically to $2 \mathrm{mg} / \mathrm{l}$ concentration of oil products. Wastewater after mechanical pretreatment is fed to the biosorbers, for the biosorption process, which takes about 8 hours. Cleaned water, having average $0.4 \mathrm{mg} / \mathrm{l}$ concentration of oil products, goes directly to the Curonian Lagoon.

When hydraulic losses become too high, then backwashing is done. Backwashing water is fed from reservoir through the drainage system. Water and excess sludge, collected during backwashing goes to the settling tank. Thickened sludge is sent to the further processing and water goes to the backwashing water reservoir and is used during the next backwashing.

Biosorber (see Figure 2) is filled with GAC and activated sludge (1). Microorganisms, which biodegrade oil products, are developing in the active sludge. Process aeration is maintained by air blowers, air is passed through the air diffusers (2), installed in the under part of the biosorber. Drain manifold (3) with laterals (4) is at the bottom of the biosorber.

Wastewater in SC "Klaipedos nafta" is specific because of high salts concentration (in ballast water salinity ranges from 120 to $3200 \mathrm{mg} / \mathrm{l}$ ). Concentration of oil products in this kind of wastewater also has high fluctuation. On purpose to speed up adaptability to wastewater, contaminated with oil products, sludge was taken from aerotanks of JSC "Mazeikiu nafta". Total initial sludge concentration in biosorbers was about $0.15 \mathrm{~g} / \mathrm{l}$.

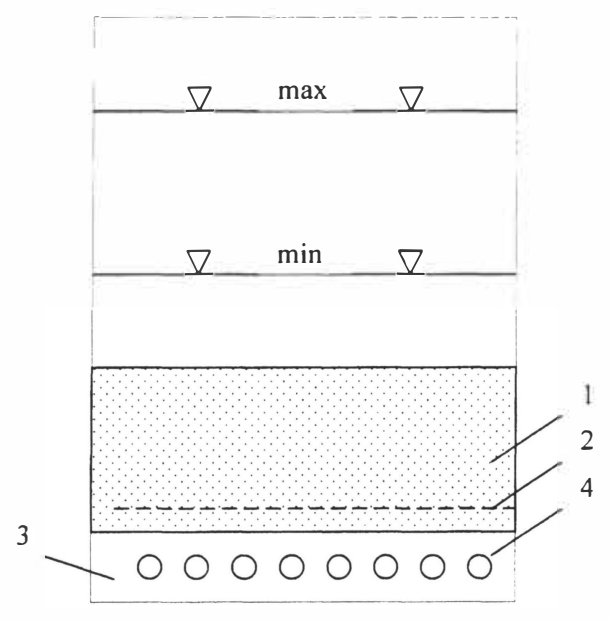

Figure 2. Principle scheme of biosorbe, 1 - Medium (GAC with active sludge layer) 2 - Air diffusers, 3 - Drain manifold, 4 -Drain laterals

The main parameters, valuing system stability are biomass amount, sorption capacity and enzymatic activity of microorganisms. Systems efficiency is characterized by Biochemical Oxygen Demand (BOD), Chemical Oxygen Demand (COD), Total Petroleum Hydrocarbons (TPH), detergents, chlorides, nitrogen, phosphorus and suspended solids concentrations. 
Sorption capacity of the sorbent was determined, using simplified method. Instead of oil products, this analysis uses other coarse molecular compound - red formazane - spirituous solution. It is colored solution, thus formazane concentration in it can be measured easily and exactly, using photocolorimetry. A sample of the sorbent is taken from the aerated biosorber. It is weighed $0.1350 \mathrm{~g}$ of wet sorbent and poured over with $5 \mathrm{ml}$ of known concentration red formazane solution. This sample is shaked for 30 minutes. Then formazane solution is poured off and its concentration is measured. The difference between concentrations is quantity of adsorbed red formazane, which shows sorbents sorption capacity.

Intensity and rate of pollutants biological oxidation in wastewater depends on albuminous catalysts or enzymes that are released by microorganisms of active sludge. Dehydrogenation reactions in the membranes and cytoplasm of microorganisms are stimulated by dehydrogenases. Total activity of these enzymes is an index of general activity of active sludge. This method is based on 2, 3, 5 - triphenil tetrazolium chloride test (TTC) colorless oxidized form reduction to red formazane under following reaction:

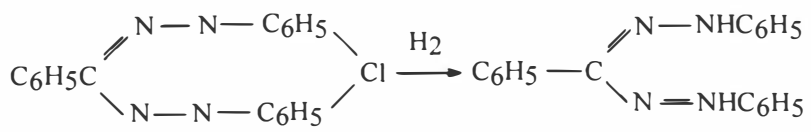

During this reaction forms a red formazane, which is insoluble in water, but solubile in ethanol, acetone, benzene and other solvents. Quantity of formed red formazane, which can be measured by colorimetry, is proportional to dehydrogenases (enzymes) activity.

$10 \mathrm{ml}$ of well mixed sample of active sludge is poured into the test-tube and then $1 \mathrm{ml}$ of $0.5 \%$ of TTC aqueous solution is added. This mixture is thermostated for 55 minutes in $37{ }^{\circ} \mathrm{C}$ temperature. Then it is centrifuged, water from the test tube is poured off and remaining sludge is poured over with ethanol. Test tube is shaked for $15-30$ minutes, until the formed red formazane melts. After all, sample is centrifuged and optical density of sample is measured.

Other parameters - BOD, COD, TPH, detergents, chlorides, nitrogen, phosphorus, suspended solids and biomass concentrations - are determined by officially certified methodic.

\section{RESULTS AND DISCUSSION}

The biosorbers installed at SC "Klaipedos nafta" are on the stage of start-up works. Nevertheless results of technological and efficiency parameters analysis indicate significant ecological benefit of the plant. The main efficiency parameter of the biosorption systems is concentration of TPH, as we are dealing with the treatment of this type of wastewater. Thus far all ballast water at SC "Klaipedos nafta" was treated using flotation systems only and the concentration of TPH in effluent was about $2 \mathrm{mg} / \mathrm{l}$ (see Figure 3). The effluent from the biosorbers contains the concentration of TPH over 4 times less (see Figure 3). 


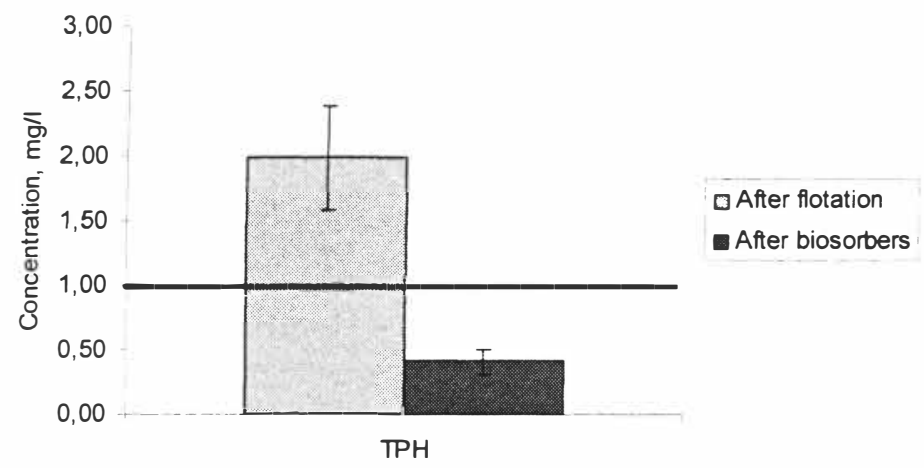

Figure 3. TPH after flotation and after biosorbers.

It is seen from Figure 3 that after flotation the concentration of TPH varies in much wider interval than after treatment in biosorbers. The results of periodical analysis of sorption capacity of the activated carbon indicate sufficient sorbent regeneration by enzymes of microorganisms. The microscopy of the active sludge samples identified microbial cultures that are capable to biodegrade oil hydrocarbons. Considering all these facts it can be stated that biosorption system is effective, stabilized and removal of oil hydrocarbons below permissible limits is ensured.

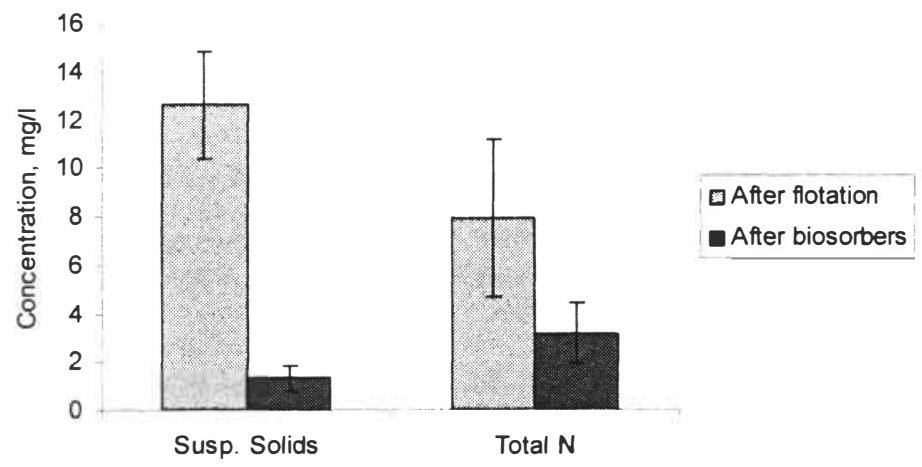

Figure 4. Suspended solids and total nitrogen after flotation and after biosorbers.

Activated carbon in biosorption system has the function of the sorbent and serves as the granular medium for the filtration. Thus concentration of suspended solids in effluent from biosorbers is about $1 \mathrm{mg} / \mathrm{l}$, when inlet water contains the concentration about $12 \mathrm{mg} / \mathrm{l}$ (see Figure 4). 
Total nitrogen analysis results show significant decrease in its concentration - from $8 \mathrm{mg} / 1$ after flotation to $3 \mathrm{mg} / \mathrm{l}$ in effluent from biosorbers (see Figure 4). During the microscopy analysis Opercularia sp. protozoa were found in the active sludge (see Figure 5). This is the proof of the presence of nitrification process as these protzoa are the indicators of nitrifying bacteria [8].

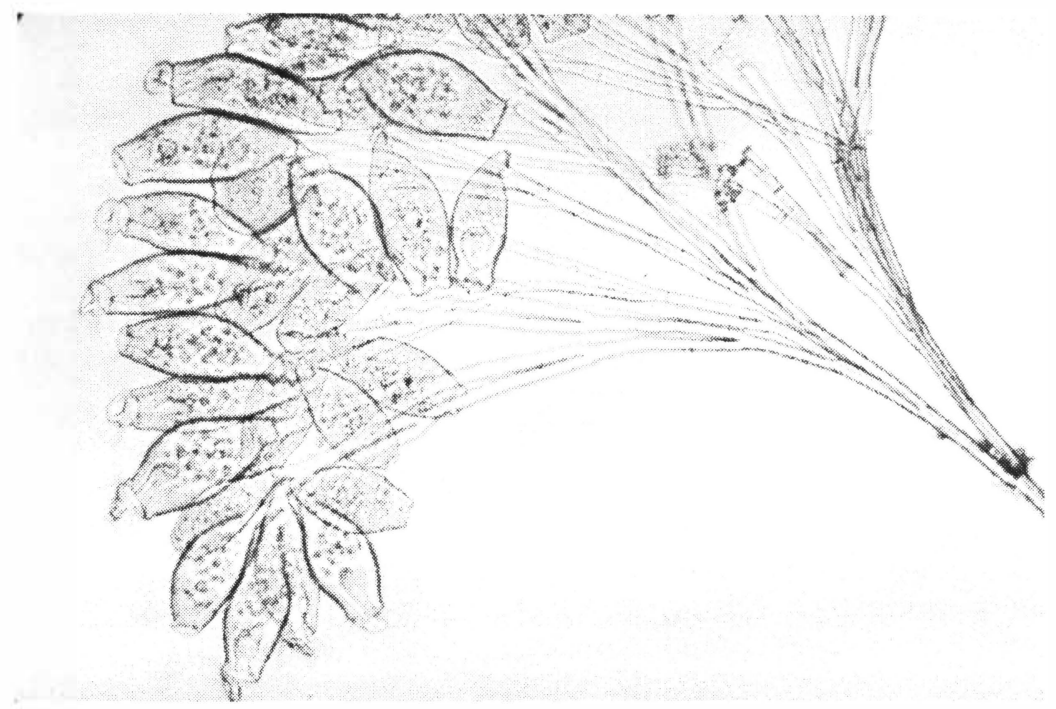

Figure 5. Opercularia sp.

$\mathrm{BOD}_{7}$ analysis results are represented in Figure 6. It has to be stressed that in raw wastewater the values of this parameter varies in rather wide interval, but effective and steady working biosorption system ensures high degree of the organics removal.

COD data showed similar tendency. The concentration of organic pollutants in raw wastewater changes every day as ballast water from tankers has the different degree of pollution. But after the treatment in biosorbers, COD value in the effluent is only the half of the environmental standard (see Figure 7).

One more aspect is very important analyzing $\mathrm{BOD}$ and $\mathrm{COD}$ parameters. The ratio $\mathrm{COD} / \mathrm{BOD}$ enables to evaluate the possibility for biological treatment of wastewater. It is estimated that biological treatment of wastewater can be effective if the ratio COD/BOD is close to approximately 1.5. The calculated ratio of biosorber's influent wastewater is approximately 4.7. High degree of organics removal proves the workability of biosorption system for removal of stable and toxic to biological life organic compounds. 


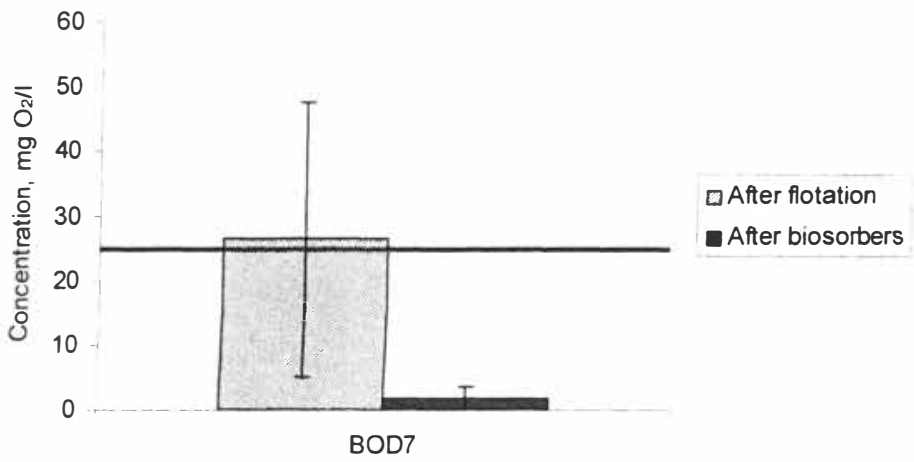

Figure 6. $\mathrm{BOD}_{7}$ after flotation and after biosorbers.

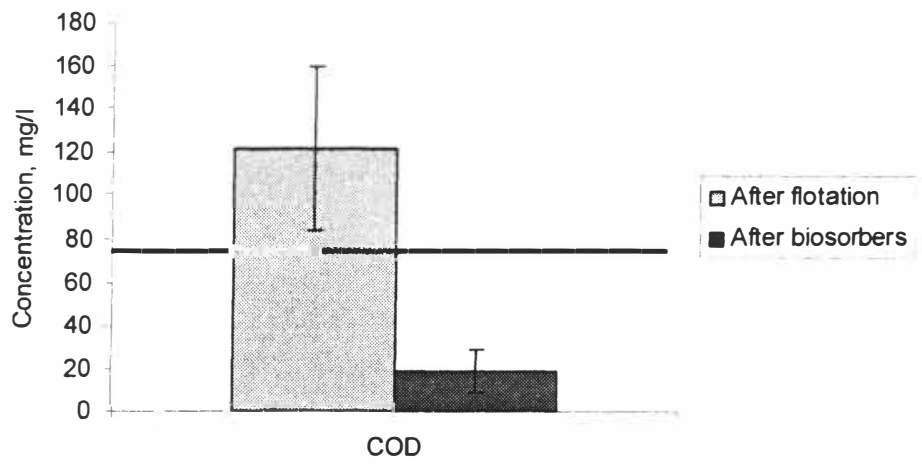

Figure 7. COD after flotation and after biosorbers.

Low levels of total phosphorus and detergents (surfactants) are detected in raw wastewater. After treatment in biosorbers the concentrations of phosphorus and detergents are reduced 4 and 3 times respectively (see Figure 8 ).

Effectiveness criteria of the system are discussed above. One of the stability parameters of biosorption system is the sorption capacity of activated carbon. The pores of activated carbon are blocked and ability for sorption is lost when water filtrates through this granular medium. In this system sorbent is being regenerated with exogenous enzymes of microorganisms. That is why there is no need to regenerate activated carbon in other more 


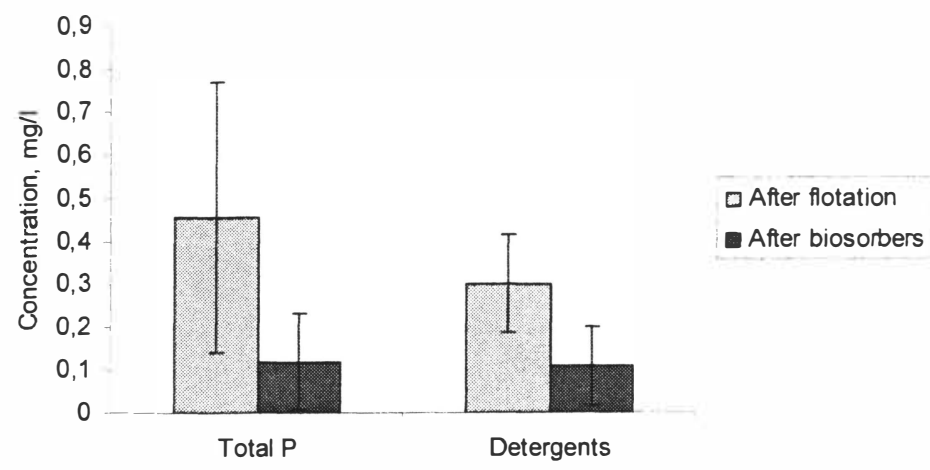

Figure 8. Total phosphorus and detergents after flotation and after biosorbers.

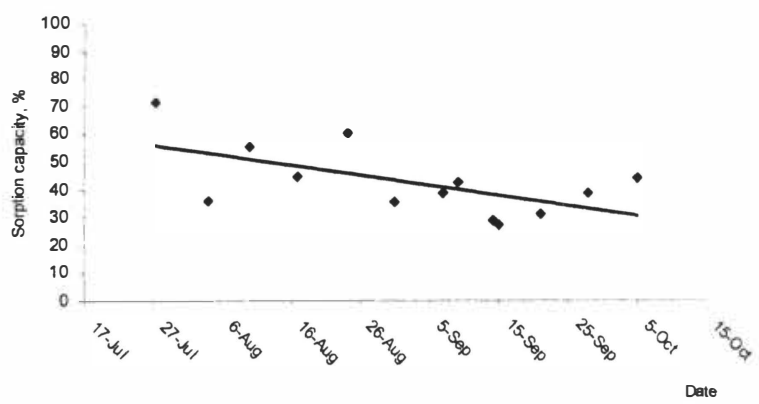

Figure 9. Sorption capacity of the activated carbon.

common ways. Thus maintenance costs of the treatment systems are reduced and the sorbent operation is prolonged. Sorption capacity of the activated carbon stays at the optimal level when stability of the overall system is reached. It can not be stated that this system is already stable as works so far are on the start-up stage (see Figure 9).

The amount of biomass, i.e. microorganisms capable to biodegrade stable organic compounds, is one of the main parameters representing system stability. Sorption capacity and biomass amount are closely linked as the principle of the system workability is the active complex of the sorbent and microorganismso Biomass amount in the biosorption system presented in this article has not reached the steady level yet. High variation of this parameter 


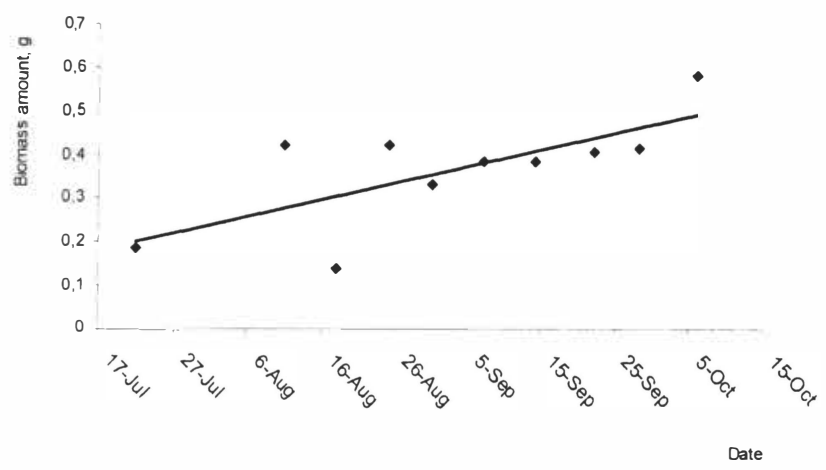

Figure 10. Biomass amount in biosorbers.

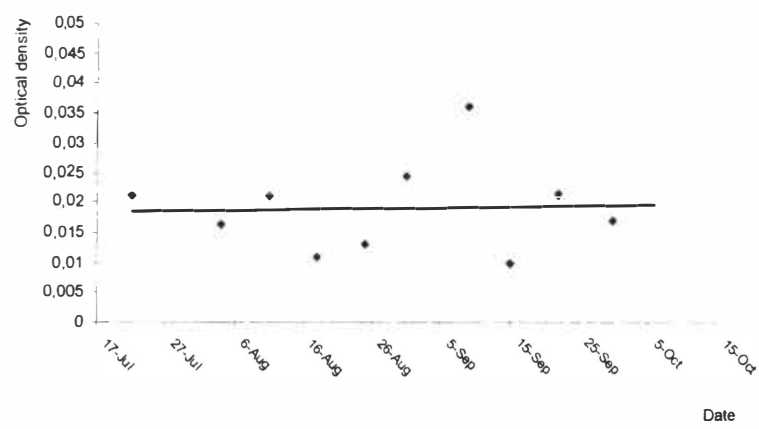

Figure 11. Enzymatic activity of microorganisms.

was estimated during the first month of the plant operation. Starting from the third month the variation became less and the small-scale increase of active sludge is being estimated (see Figure 10).

Degree of biological oxidation and rate of wastewater pollutants removal depends on albuminous catalysts or enzymes that are present in microorganisms of active sludge. During biological oxidation, hydrogen is removed from organic substrate. These reactions in cell membrane and cytoplasm are stimulated by enzymes - dehydrogenases. Total activity of these enzymes is the indicator of total enzymatic (or biochemical) activity of active sludge. This parameter is analyzed under to methodology presented in previous chapter. Potential of the active sludge to biodegrade water pollutants is described according to the optical density of spirituous solution formed during the analysis. It is estimated that enzymatic activity of 
active sludge in aeration tanks is satisfactory when optical density of the solution is about 0.1 . According to this theory oxidation potential of the sludge in biosorbers is too low (see Figure 11), but high degree of pollutants removal promote further investigation of the system.

\section{CONCLUSIONS}

1. COD, BOD and other analysis results show high variation of pollutants in the influent wastewater, but after treatment in biosorbers the quality of the effluent is rather high and stable.

2. It is recommended to apply biological treatment for wastewater when ratio COD/BOD is approximately 1.5 , but this system works effectively even if ratio $\mathrm{COD} / \mathrm{BOD}$ in influent water is above 4.7 .

3. The concentration of total nitrogen is reduced two times because Mean Cell Residence Time is high and favorable conditions for denitrification are present in deep layers of GAC and biomass complex and in all biosorber volume when aeration is stopped for draining and filling up the biosorbers.

4. Despite high variation of pollutants concentration in biosorber's influent, the effluent quality is high and constant.

5. Sorption capacity of the biologically activated sorbent can be regenerated during biochemical processes.

6. Enzymatic activity of active sludge remained almost at the steady state.

\section{ACKNOWLEDGEMENT}

We are grateful to SC „Klaipedos nafta“ for possibility to use the laboratory facilities in further investigation of biosorption process in real application.

\section{REFERENCES}

[1] Cipinyte V., 2000. Biological treatment of environment polluted with oil hydrocarbons. Summary of doctoral thesis. Vilnius, Lithuania.

[2] Melin Esa, 1997. Biodegradation and Treatment of Organic Environmental Contaminants by Fluidized-Bed Enrichment Cultures. Thesis for the degree of Doctor of Technology. Tampere, Finland.

[3] Matuzevicius.A., 1998. Active sludge in wastewater treatment: lecture material. Technika, Vilnius, Lithuania.

[4] Fadi Gebara, Activated sludge biofilm wastewater treatment system. Water Research. 33(1), 230-238.

[5] Dalmacija B., Tamas Z., Miskovic D., 1992. The biosorption of selected pesticides from water by biologically activated carbon. Water Science and Technology 26 (9-11), 1991 1994.

[6] Maier M., Maier D., Lloyd B. J., 1999. Conference on Biofilm Systems, program and proceedings October 17 -20. New York, pp. 633-643.

[7] Tumbas I.I, Dalmacija B., Tamas Z., Karlovic E., Apr 1998. Reuse of biologically regenerated activated carbon for phenol removal. Water Research 32(4), 1085-1094.

[8] Environmental Leverage Inc. Web Site, 200509 14, USA, http://www.environmentalleverage.com. 